\title{
Oophorectomy, Menopause, Estrogen, and Cognitive Aging: The Timing Hypothesis
}

\author{
Walter A. Rocca ${ }^{a, b}$ Brandon R. Grossardt ${ }^{c}$ Lynne T. Shuster ${ }^{d}$ \\ ${ }^{a}$ Division of Epidemiology, Department of Health Sciences Research, ${ }^{b}$ Department of Neurology, \\ 'Division of Biomedical Statistics and Informatics, Department of Health Sciences Research, and \\ dWomen's Health Clinic, Department of Internal Medicine, College of Medicine, Mayo Clinic, \\ Rochester, Minn., USA
}

\section{Key Words}

Oophorectomy $\cdot$ Menopause $\cdot$ Estrogen .

Neuroprotection • Dementia $\cdot$ Cognitive impairment •

Timing hypothesis

\begin{abstract}
Background: The concept of neuroprotective effects of estrogen in women remains controversial. Objective: To explore the timing hypothesis in relation to cognitive aging and dementia. Methods: We reviewed existing literature, conducted some reanalyses, and combined results graphically. Results: Current evidence suggests that estrogen may have either protective effects or harmful effects on the brain depending on age, type of menopause (natural versus surgical), or stage of menopause. The comparison of women with ovarian conservation versus women who underwent bilateral oophorectomy provided evidence for a sizeable neuroprotective effect of estrogen in women in the premenopausal years (most commonly before age 50 years). Several case-control studies and cohort studies also showed a neuroprotective effect in women who received estrogen treatment in the early postmenopausal phase (most commonly at ages 50-60 years). However, recent clinical trials showed that women who initiated estrogen treatment in the late postmenopausal phase (ages 65-79 years) experienced an increased risk of dementia and cognitive decline. Conclu-
\end{abstract}

sion: The neuroprotective effects of estrogen depend on age, type of menopause, and stage of menopause (timing hypothesis).

Copyright $\odot 2010$ S. Karger AG, Basel

\section{Introduction}

The concept of neuroprotective effects of estrogen in women remains controversial because these effects may vary with the timing of treatment $[1,2]$. Thus, we combined findings from both observational studies and clinical trials to explore the timing hypothesis in relation to cognitive aging and dementia. This article is a review of existing literature and includes some reanalysis of published data and the graphic combination of results. Figures 1 and 2 illustrate the existing evidence in support of a neuroprotective effect of estrogen in women.

\section{Evidence of Neuroprotective Effects of Estrogen in Animal Experiments}

Most experiments involved the removal of the ovaries and subsequent administration of estrogen in female animals. These experiments suggested several mechanisms

\section{KARGER}

두 2010 S. Karger AG, Basel

Fax +41613061234

E-Mail karger@karger.ch

www.karger.com
Accessible online at:

www.karger.com/ndd
Walter A. Rocca, MD, MPH

Division of Epidemiology, Department of Health Sciences Research

Mayo Clinic, 200 First Street SW

Rochester, MN 55905 (USA)

Tel. +1 507284 3568, Fax +1 507284 1516, E-Mail rocca@ mayo.edu 
Fig. 1. Four possible clinical situations relevant to the timing hypothesis of estrogen neuroprotection. a Women who underwent bilateral oophorectomy early in life experienced premature estrogen deficiency and increased risk of cognitive impairment or dementia. b Women who underwent bilateral oophorectomy and were treated with estrogen through age 50 years or later had the same risk of cognitive impairment or dementia as the general population. c Women who underwent natural menopause and were treated with estrogen in the early postmenopausal phase (most commonly at ages 50-60 years) had a reduced risk of cognitive impairment or dementia. d Women who underwent natural menopause or surgical menopause (hysterectomy with or without bilateral oophorectomy) and initiated estrogen treatment (ET) at ages 65-79 years had an increased risk of cognitive impairment and dementia. The apparent paradox of these four clinical situations is resolved by postulating an interaction between timing and ET (timing hypothesis).

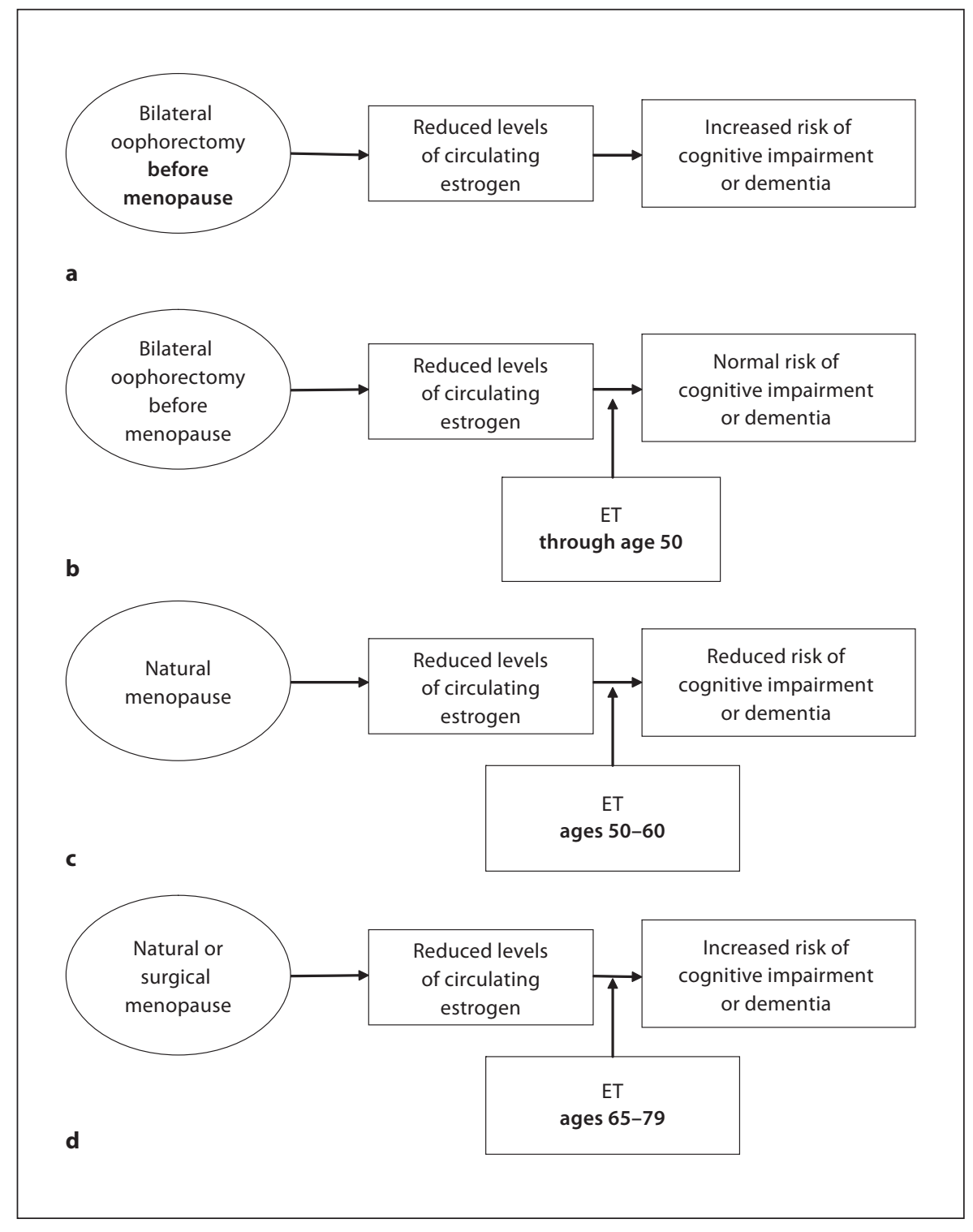

of action. (1) Estrogen improves synapse formation on dendritic spines in hippocampi of ovariectomized rats [3, 4]. (2) Estrogen may improve cerebral blood flow and glucose metabolism, and it may act as an antioxidant [3-5]. (3) Estrogen increases choline acetyltransferase activity in the basal forebrains and hippocampi of ovariectomized rats [5, 6]. (4) Estrogen reduces the deposition of $\beta$-amyloid in the brain, whereas progesterone has the opposite effect [7]. (5) Estrogen prevents mitochondrial damage [8]. Thus, there is strong and consistent evidence of neuroprotective effects of estrogen in animal models $[2,9]$.

\section{Evidence of Neuroprotective Effects of Estrogen in Women before the Age of Natural Menopause}

Important observations on the effects of estrogen in younger women come from studies of women who underwent bilateral oophorectomy before reaching natural menopause. The hormonal changes occurring after bilateral oophorectomy in premenopausal women are different from those occurring during natural menopause or after bilateral oophorectomy in women who already experienced natural menopause. In particular, bilateral oophorectomy before menopause causes an abrupt deficiency of estrogen as well as a deficiency of 
Fig. 2. The effect of estrogen on the risk of cognitive decline or dementia varies with age, type of menopause, and stage of menopause (relative risk estimated by an odds ratio or a hazard ratio and $95 \%$ confidence intervals; logarithmic scale). a Women with ovarian conservation before menopause (most commonly before age 50 years) have a reduced long-term risk of cognitive decline or dementia compared to women who underwent bilateral oophorectomy. b Treatment with estrogen in the early postmenopausal phase (most commonly at ages $50-60$ years) is associated with a reduced long-term risk of cognitive decline or dementia. c Initiation of ET in the late postmenopausal phase (ages 6579 years) is associated with an increased risk of cognitive impairment or dementia. $\mathrm{CEE}=$ Conjugated equine estrogen; $\mathrm{HR}=$ hazard ratio; $\mathrm{MPA}=$ medroxyprogesterone acetate; $\mathrm{OR}=$ odds ratio.

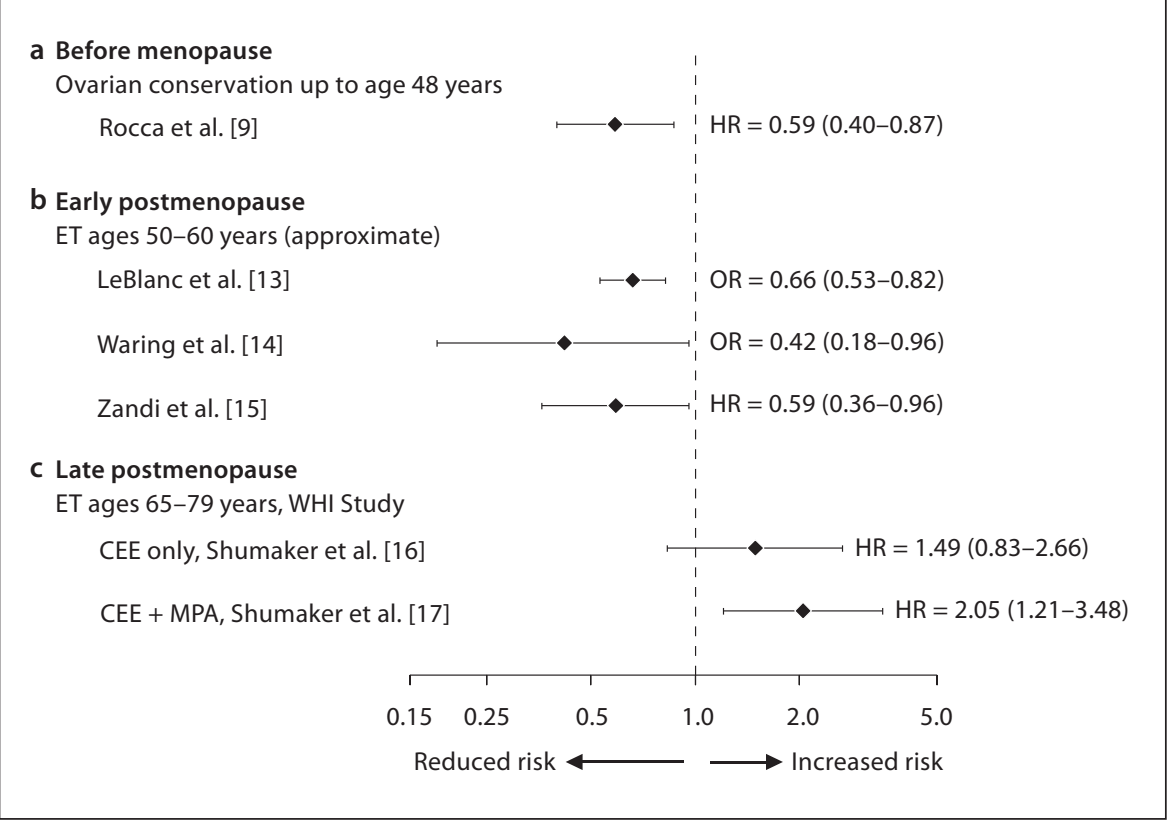

progesterone and testosterone, and a disruption of the hypothalamic-pituitary-ovarian axis [8]. The disruption of the axis is associated with an abrupt increase in gonadotropins (luteinizing hormone and follicle-stimulating hormone).

The available scientific evidence on cognitive sequelae of bilateral oophorectomy is limited $[9,10]$. However, the recent Mayo Clinic cohort study showed an almost doubled long-term risk of cognitive impairment or dementia in women who underwent oophorectomy before menopause (fig. 1a) [9]. The study also showed a trend of increasing risk of cognitive impairment and dementia with younger age at time of oophorectomy [9]. It remains uncertain whether the harmful effects of bilateral oophorectomy are mediated entirely by estrogen deficiency or also by other hormonal mechanisms $[8$, 11]. However, women who underwent bilateral oophorectomy before age 49 years, but received estrogen treatment (ET) through age 50 years or longer, did not experience an increased risk of cognitive impairment or dementia (fig. 1b) [9].

The only experimental evidence specific for ET after bilateral oophorectomy in women comes from the clinical trials of Sherwin and colleagues involving small groups of women with short-term treatment and minimal follow-up (2-3 months). These short-term trials consistently suggested a neuroprotective effect of estrogen when initiated after oophorectomy [12].

\section{Evidence of Neuroprotective Effects of Estrogen in Women in the Early Postmenopausal Phase}

Case-control and cohort studies have consistently shown a protective effect when ET was started in early postmenopause (most commonly at ages $50-60$ years; fig. 1c) [13-15]. These observational findings have been criticized because they could be the result of confounding. It is argued that other factors such as higher socioeconomic status, higher education, or better general health may be the real causes of neuroprotection and that ET is only a surrogate marker. However, it is also possible that the observational findings are not due to confounding and that the contradiction between observational studies and clinical trials is due to timing differences.

\section{Evidence of Deleterious Effects of Estrogen Initiated in the Late Postmenopausal Phase}

The Women's Health Initiative (WHI) clinical trials showed an increased risk of dementia or mild cognitive impairment among women who initiated treatment with estrogen alone or in combination with progestin at ages 65-79 years (fig. 1d) [16, 17]. However, these trials focused on the effects of ET initiated many years after the onset of natural menopause, and the discrepancy be- 
tween the WHI results and observational data may be explained by the timing of initiation of estrogen $[1,2]$. Indeed, the effects of estrogen on the brain are probably preventive, and when vascular or degenerative lesions have occurred, estrogen cannot reverse the lesions.

The results from the WHI clinical trials have been inappropriately extrapolated from women in the late postmenopausal phase to younger women in the early postmenopausal phase, and to much younger women who underwent bilateral oophorectomy before menopause. Thus, after publication of the WHI results, many women discontinued ET or avoided starting ET at all ages, including women who underwent bilateral oophorectomy before age 50 years [18-20].

\section{Conclusions}

A combination of current scientific evidence from animal studies and from both observational studies and clinical trials suggests that estrogen is neuroprotective; however, the neuroprotective effects are dependent on age, type of menopause, and stage of menopause. The apparent contradiction of results from observational studies versus results from clinical trials may be explained by the timing hypothesis (fig. 2).

\section{Acknowledgments}

This research was supported by the National Institute of Neurological Disorders and Stroke (grant R01 NS033978) and the National Institute of Arthritis and Musculoskeletal and Skin Diseases (grant R01 AR030582).

\section{References}

1 Manson JE, Bassuk SS, Harman SM, Brinton EA, Cedars MI, Lobo R, Merriam GR, Miller VM, Naftolin F, Santoro N: Postmenopausal hormone therapy: new questions and the case for new clinical trials. Menopause 2006; 13:139-147.

2 Siegfried T: Neuroscience: it's all in the timing. Nature 2007;445:359-361.

- 3 McEwen BS, Alves SE: Estrogen actions in the central nervous system. Endocr Rev 1999:20:279-307.

4 Monk D, Brodaty $\mathrm{H}$ : Use of estrogens for the prevention and treatment of Alzheimer's disease. Dement Geriatr Cogn Disord 2000; 11:1-10.

5 Gibbs RB, Aggarwal P: Estrogen and basal forebrain cholinergic neurons: implications for brain aging and Alzheimer's disease-related cognitive decline. Horm Behav 1998; 34:98-111.

6 Markowska AL, Savonenko AV: Effectiveness of estrogen replacement in restoration of cognitive function after long-term estrogen withdrawal in aging rats. J Neurosci 2002;22:10985-10995.

7 Huang J, Guan H, Booze RM, Eckman CB, Hersh LB: Estrogen regulates neprilysin activity in rat brain. Neurosci Lett 2004;367: $85-87$.

8 Morrison JH, Brinton RD, Schmidt PJ, Gore AC: Estrogen, menopause, and the aging brain: how basic neuroscience can inform hormone therapy in women. J Neurosci 2006;26:10332-10348.
9 Rocca WA, Bower JH, Maraganore DM, Ahlskog JE, Grossardt BR, de Andrade M, Melton LJ 3rd: Increased risk of cognitive impairment or dementia in women who underwent oophorectomy before menopause. Neurology 2007;69:1074-1083.

10 Shuster LT, Gostout BS, Grossardt BR, Rocca WA: Prophylactic oophorectomy in premenopausal women and long-term health Menopause Int 2008;14:111-116.

11 Rocca WA, Shuster LT, Grossardt BR, Maraganore DM, Gostout BS, Geda YE, Melton LJ 3rd: Long-term effects of bilateral oophorectomy on brain aging: unanswered questions from the Mayo Clinic Cohort Study of Oophorectomy and Aging. Womens Health (Lond Engl) 2009;5:39-48.

12 Lethaby A, Hogervorst E, Richards M, Yesufu A, Yaffe K: Hormone replacement therapy for cognitive function in postmenopausal women. Cochrane Database Syst Rev 2008: CD003122.

13 LeBlanc ES, Janowsky J, Chan BK, Nelson HD: Hormone replacement therapy and cognition: systematic review and meta-analysis. JAMA 2001;285:1489-1499.

14 Waring SC, Rocca WA, Petersen RC, O’Brien PC, Tangalos EG, Kokmen E: Postmenopausal estrogen replacement therapy and risk of AD: a population-based study. Neurology 1999;52:965-970.

15 Zandi PP, Carlson MC, Plassman BL, WelshBohmer KA, Mayer LS, Steffens DC, Breitner JC: Hormone replacement therapy and incidence of Alzheimer disease in older women: the Cache County Study. JAMA 2002;288: 2123-2129.
16 Shumaker SA, Legault C, Kuller L, Rapp SR, Thal L, Lane DS, Fillit H, Stefanick ML, Hendrix SL, Lewis CE, Masaki K, Coker LH: Conjugated equine estrogens and incidence of probable dementia and mild cognitive impairment in postmenopausal women: Women's Health Initiative Memory Study. JAMA 2004;291:2947-2958.

-17 Shumaker SA, Legault C, Rapp SR, Thal L, Wallace RB, Ockene JK, Hendrix SL, Jones BN 3rd, Assaf AR, Jackson RD, Kotchen JM, Wassertheil-Smoller S, Wactawski-Wende J: Estrogen plus progestin and the incidence of dementia and mild cognitive impairment in postmenopausal women: the Women's Health Initiative Memory Study: a randomized controlled trial. JAMA 2003;289:26512662.

18 Buist DS, Newton KM, Miglioretti DL, Beverly K, Connelly MT, Andrade S, Hartsfield CL, Wei F, Chan KA, Kessler L: Hormone therapy prescribing patterns in the United States. Obstet Gynecol 2004;104:1042-1050.

19 Haas JS, Kaplan CP, Gerstenberger EP, Kerlikowske K: Changes in the use of postmenopausal hormone therapy after the publication of clinical trial results. Ann Intern Med 2004;140:184-188.

20 Hersh AL, Stefanick ML, Stafford RS: National use of postmenopausal hormone therapy: annual trends and response to recent evidence. JAMA 2004;291:47-53. 